\title{
Bystander effect in human lymphocytes incubated with irradiated mitochondrial DNA deficient yeast cells
}

\author{
O.P. Vasylenko, O.V. Pronina and S.R. Rushkovsky
}

National Taras Shevchenko University of Kyiv, Volodymyrska, 64, 01033 Kyiv, Ukraine

\begin{abstract}
The comparison of strength of bystander effect induction in human lymphocytes by rho ${ }^{0}$ (complete loss of mitochondrial DNA) and rho $^{+}$(with fully functional mtDNA) strains of Saccharomyces cerevisiae was carried out. The cultures of human peripheral blood were experimentally contaminated with nonirradiated or X-ray irradiated yeast cells (haploid rho $^{0}$ and $\mathrm{rho}^{+}$strains of S. cerevisiae). The doses of irradiation were 1 and $10 \mathrm{~Gy}$. Well spread human metaphases were scored for chromosomal aberrations (CA). It was found that nonirradiated yeast cells (no matter hho $^{0}$ or rho $^{+}$) had no effect on lymphocytes chromosomal stability. Statistically significant increased level of CA was observed in lymphocytes incubated with irradiated rho $^{+}$yeast cells. The increasing of the CA was dose independent. However, after cocultivation with irradiated rho ${ }^{0}$ cells the bystander effect was revealed for dose 10 Gy only and his manifestation was mild in comparison with rho ${ }^{+}$data. Thus, our findings suggest that strength of bystander effect depends on existence of mitochondrial DNA and normally functioning mitochondria.
\end{abstract}

\section{INTRODUCTION}

The existence of a bystander effect (BE) in which cells not exposed to ionizing radiation respond to a stress signal from nearby irradiated cells is now well established [1]. This phenomenon has been described in wide variety of vertebrate cell types, and to a lesser extent in other Metazoa cells and several unicellular organisms [2,3]. It was shown that BE is not cell-type dependent and can be induced in mixed cell cultures containing cells of different lines or cells derived from different species [4]. In addition, there is evidence for the existence of BE-like interactions in vivo in animals [5], in plants [6], as well as between cohabiting individuals of the same species [7, 8]. The topical question is whether the mechanisms of BE induction are universal for all organisms, and therefore whether it can occur between the cells of evolutionary distant organisms? Recently we have demonstrated the evident bystander effect in human lymphocytes incubated with irradiated yeast Saccharomyces cerevisiae [9]. Thus, the yeastlymphocyte mixed culture, when yeast $S$. cerevisiae cells are used as potential donors for the bystander signal, whereas human lymphocytes are a potential receptor cells, may be advantageous and easyto-use system for investigation of BE between evolutionary very distant organisms. Another matter of importance is the nature of the stress signals that generate bystander response. Early studies have been shown that mitochondria and reactive oxygen species appear to be important to the coordination and regulation of BE [10]. For example, Chen et. al. reported that mtDNA-depleted cells have an attenuated $\mathrm{BE}$ induction [4]. The purpose of the present study was comparison of strength of bystander effect in human lymphocytes induction by rho ${ }^{0}$ (complete loss of mitochondrial DNA) and rho ${ }^{+}$(with fully functional mtDNA) strains of S. cerevisiae.

\section{MATERIALS AND METHODS}

\subsection{Yeast strains}

Haploid DLY640 strain S. cerevisiae (W303 background [11]) was kindly provided by Dr Mikhajlo K. Zubko (University of Newcastle, United Kingdom) and has genotype MATa ade2-1 trp1-1 
can1-100 leu2-3,112 his3-11, 15 ura3 GAL+ [psi+] ssd1-d2 RAD5. The rho ${ }^{0}$ derivative strain was obtained by cultivation of the rho ${ }^{+}$cells in $2 \mathrm{ml}$ of the liquid YPD medium containing $10 \mu \mathrm{g} / \mathrm{ml}$ of ethidium bromide at the $28^{\circ} \mathrm{C}$ without hesitation. After incubation the yeast cells were washed in distilled water twice and spread on surface of the solid YPD medium to receive single colonies. The mutant clones were selected by inability to grow on YPG medium (contain glycerol as carbon source). Control of the loss of mitochondrial DNA was performed by luminescent microscopy after DAPI vital staining. Stationary phase yeast cells were received from 5 days old colonies grown on YPD medium at $28^{\circ} \mathrm{C}$. After incubations cells were washed twice by sterile normal saline solution and counted in hemocytometer. The cells of rho ${ }^{0}$ and rho $^{+}$strains were exposed to X-rays (RUM-17, Mosrentgen, Russia; $0,33 \mathrm{~Gy} / \mathrm{min}, 200 \mathrm{keV}$, filtered through $0,5 \mathrm{~mm} \mathrm{Cu}$ ) at the dose rates of 1 and $10 \mathrm{~Gy}$.

\subsection{Yeast-human lymphocytes culture and human chromosome slides preparation}

Blood samples for chromosome assays were obtained by venepuncture from healthy volunteer donors. Samples of whole blood $(1 \mathrm{ml})$ was cultivated in $5 \mathrm{ml}$ of RPMI- 1640 medium with $10 \mu \mathrm{g}$ per ml of PHA-P (Sigma, USA). At the beginning of the incubation procedure, set of cultures were experimentally contaminated with nonirradiated or X-ray irradiated yeast cells ( $\mathrm{rho}^{0}$ and rho ${ }^{+}$strains) to the number of $10^{6}$ cells per lymphocytes culture. Cultures were incubated at $37^{\circ} \mathrm{C}$ for $52 \mathrm{~h}$. Prior to the end of the culturing (1.5-2 hours), colchicine ( $1 \mu \mathrm{g} / \mathrm{ml}$, final concentration) was added to each culture to arrest mitosis. After cultivation cells were treated with $0.075 \mathrm{M} \mathrm{KCl}$ solution and fixed in four changes of methanol:acetic acid mixture $(3: 1)$. To prepare metaphase plates, the cell suspension was dropped onto cool moist slides and dried.

\subsection{Chromosome analysis}

All slides were stained with $2 \%$ Giemsa mixture in distilled water for $20 \mathrm{~min}$. (without banding). Well spread metaphases (100-200 for each variant) were scored under the light microscope (ML-2, "LOMO", $\times 1000$ magnification) for chromatide and chromosome type lesions. Chromatide gaps were not scored according to generally accepted criteria [12]. Scoring of chromatide breaks was performed accoding CBIC recommendation [13]. Plates with less than 44 chromosome were not considered. Statistical processing was carried out by the standard methods [14].

\section{RESULTS AND DISCUSSION}

\subsection{Chromosomal instability in human lymphocytes cocultivated with irradiated rho ${ }^{+}$ S. cerevisiae cells}

The level of the chromosomal aberrations (CA) in human lymphocytes cocultivated with nonirradiated rho $^{+}$yeast cells was quite similar to control $(2.67 \pm 0.93 \%$ for control; $3.00 \pm 0.98 \%$ for lymphocytes after incubation with nonirradiated $\mathrm{rho}^{+}$yeast cells, $p>0.05$ ). Therefore we conclude that nonirradiated yeast cells had no effect on lymphocytes chromosomal stability. Statistically significant increased level of CA was observed in lymphocytes incubated with irradiated rho ${ }^{+}$S. cerevisiae: $2.67 \pm$ $0.93 \%$ in control, $7.50 \pm 1.29 \%$ after incubation with $1 \mathrm{~Gy}$ irradiated yeast cells and $8.33 \pm 1.60 \%$ after incubation with $10 \mathrm{~Gy}$ irradiated yeast cells, $p<0.01$ (Fig. 1). It should be pointed that the increasing of the CA was dose independent. These results suggest that irradiated rho $^{+}$yeast cells can generate bystander signals induced the evident bystander effect in human lymphocytes.

Analysis of the spectrum of chromosomal aberration indicated chromatid type aberrations as the main chromosomal lesions for lymphocytes after incubation with $10 \mathrm{~Gy}$ irradiated rho $^{+}$yeast cells ( $6.33 \pm 1.41 \%$ - the chromatid type aberrations; $2.00 \pm 0.81 \%$ - the chromosome type aberrations, $p<$ 0.01 ) (Fig. 2). For lymphocytes after incubation with $1 \mathrm{~Gy}$ irradiated rho ${ }^{+}$yeast cells difference between 


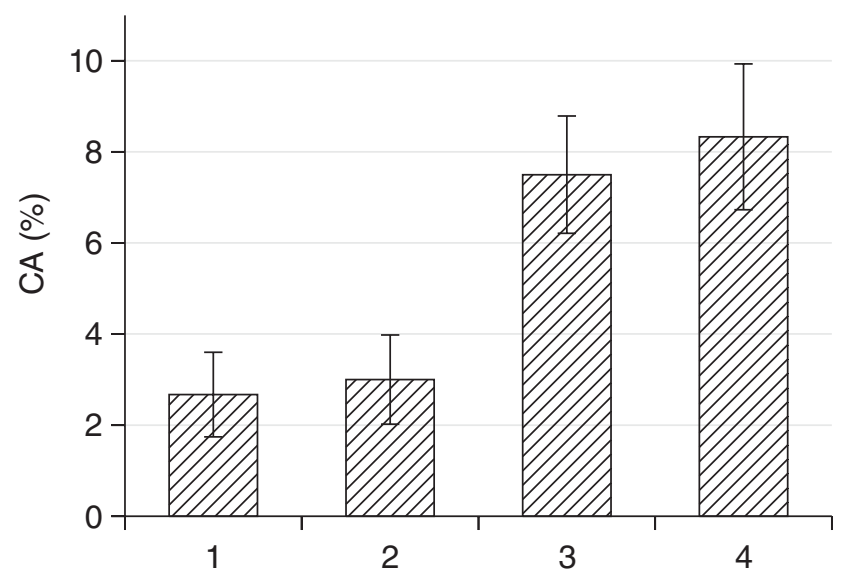

Figure 1. Levels of CA in lymphocytes incubated with irradiated rho ${ }^{+}$cells of $S$. cerevisiae. 1 - control, 2 lymphocytes incubated with non-irradiated yeast, 3 - lymphocytes incubated with 1 Gy irradiated yeast cells, 4 - lymphocytes incubated with $10 \mathrm{~Gy}$ irradiated yeast cells.

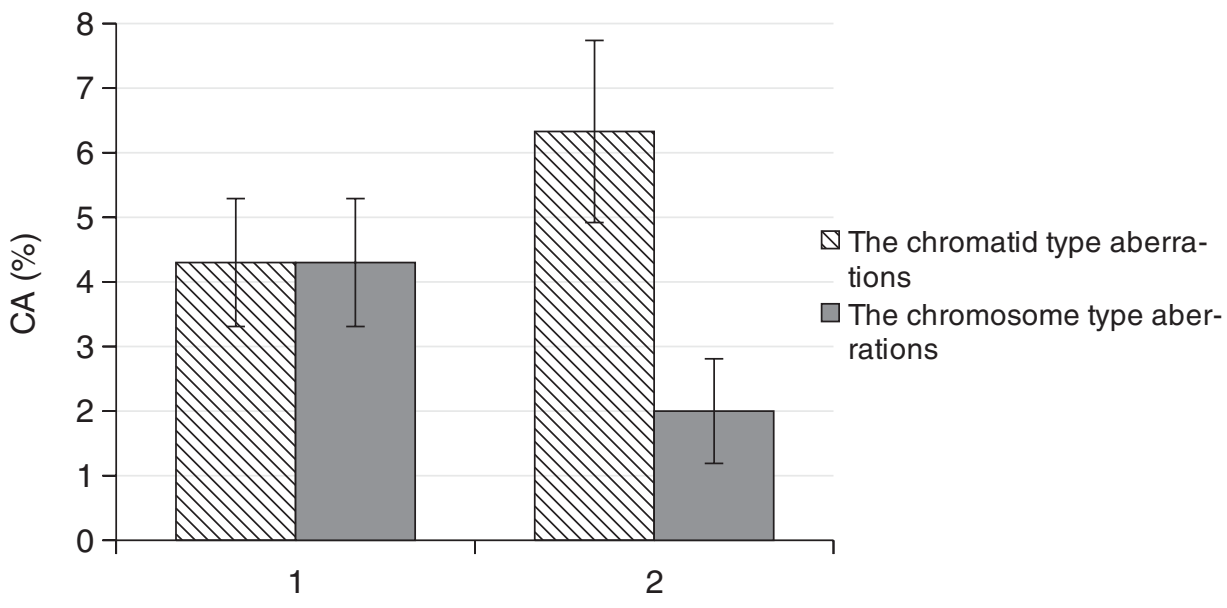

Figure 2. Chromatid to chromosome aberration types ratio in lymphocytes after incubation with $1 \mathrm{~Gy}$ irradiated rho $^{+}$yeast cells (1) and lymphocytes after incubation with $10 \mathrm{~Gy}$ irradiated rho ${ }^{+}$yeast cells (2).

level of the chromosome and chromatid type aberrations were statistically insignificant $(4.30 \pm 0.99 \%$ - the chromatid type aberrations; $4.30 \pm 0.99 \%$ - the chromosome type aberrations, $p>0.05$ ).

\subsection{Manifestation of the bystander effect in lymphocytes that induced by irradiated rho ${ }^{0}$ yeast cells}

To investigate the role of mitochondria in $\mathrm{BE}$ induction the lymphocytes were incubated with rho ${ }^{0}$ S. cerevisiae cells. It was found that nonirradiated rho ${ }^{0}$ yeast cells, similar to rho ${ }^{+}$cells, had no effect on lymphocytes chromosomal stability: $1.00 \pm 0.70 \%$ for control; $1.00 \pm 0.70 \%$ for lymphocytes after incubation with nonirradiated rho ${ }^{0}$ yeast cells, $p>0.05$. After cocultivation human lymphocytes with irradiated rho ${ }^{0}$ cells the bystander effect was revealed for the dose $10 \mathrm{~Gy}$ only $(2.00 \pm 0.81 \%$ - for incubation with $1 \mathrm{~Gy}$ irradiated rho ${ }^{0}$ yeast cells, $p>0.05$ by comparison with control; $3.67 \pm 1.09 \%$ - for incubation with $10 \mathrm{~Gy}$ irradiated rho ${ }^{0}$ yeast cells, $p<0.01$ by comparison with control). This 


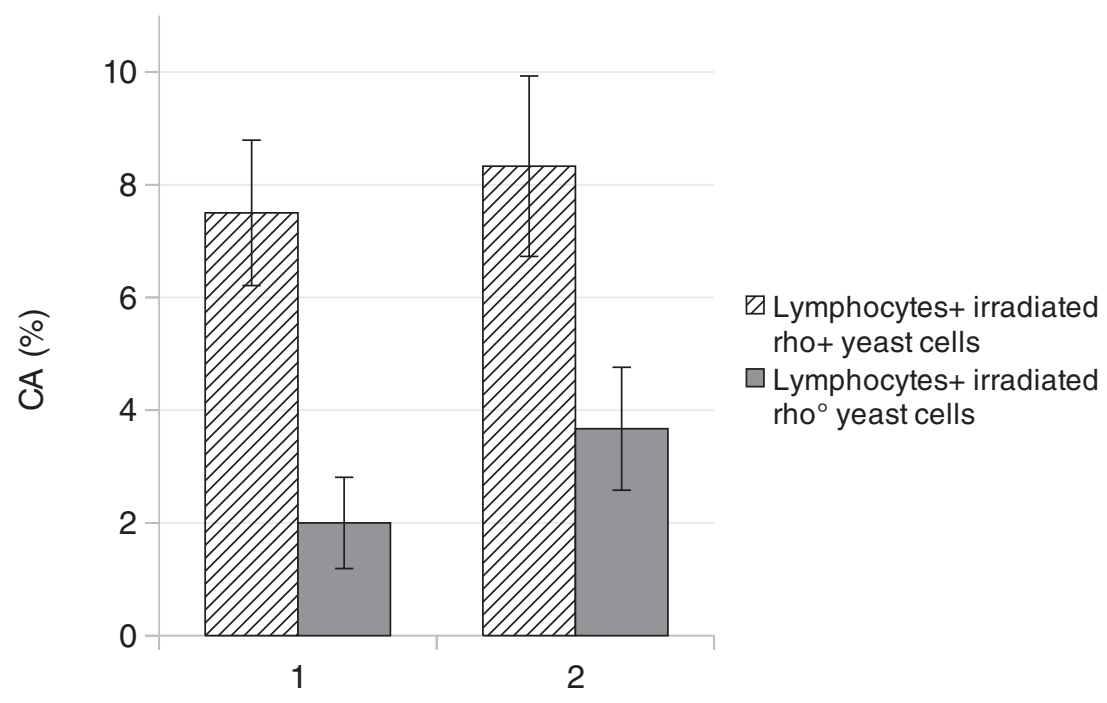

Figure 3. Comparison of the level of chromosomal aberrations in human lymphocytes after cocultivation with the rho $^{+}$and rho ${ }^{0}$ yeast icells rradiated with doses of $1 \mathrm{~Gy}(1)$ and $10 \mathrm{~Gy}(2)$.

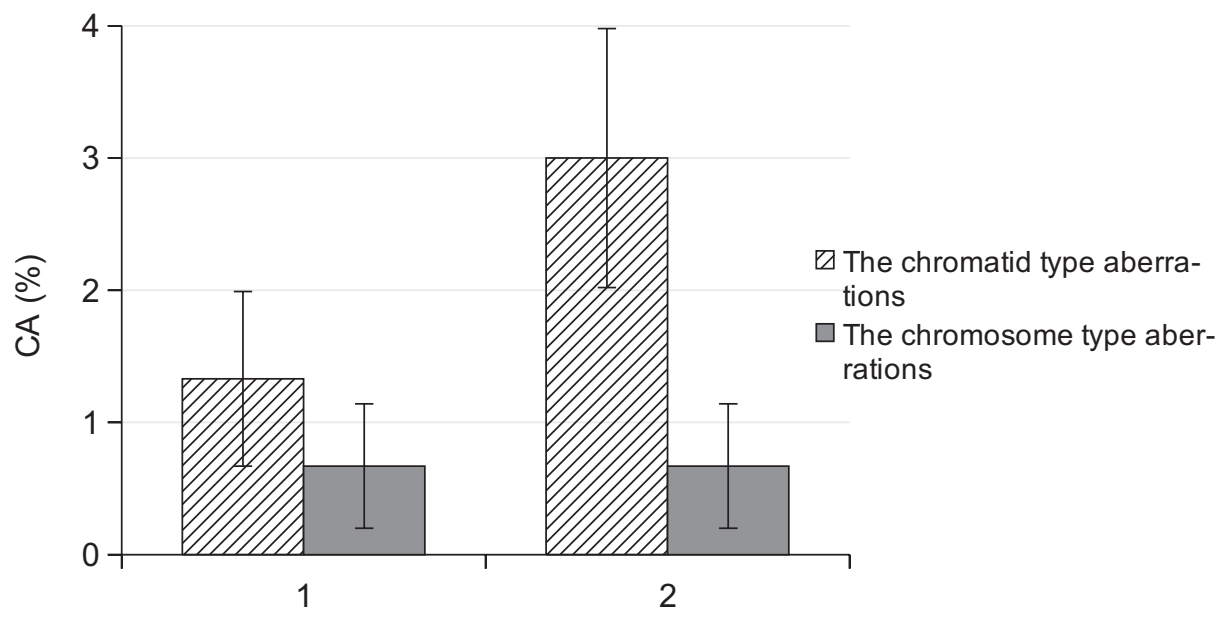

Figure 4. Chromatid to chromosome aberration types ratio in lymphocytes after incubation with $1 \mathrm{~Gy}$ irradiated rho $^{+}$yeast cells (1) and lymphocytes after incubation with $10 \mathrm{~Gy}$ irradiated rho ${ }^{0}$ yeast cells (2).

result indicated that induction of the bystander effect by $10 \mathrm{~Gy}$ irradiated rho ${ }^{0}$ yeast cells was mild in comparison with rho $^{+}$data. Comparison the level of CA in human lymphocytes after contamination human lymphocytes with irradiated rho $^{+}$and rho $^{0}$ strains of yeast cells (Fig. 3) clearly shows that irradiated rho $^{+}$yeast cells induced $\mathrm{BE}$ is much stronger than the rho ${ }^{0}$ cells. These results confirm the view that strength of bystander effect depends on existence of mitochondrial DNA and normally functioning mitochondria [4].

Analysis of the spectrum of chromosomal aberration indicated chromatid type aberrations as the main chromosomal lesions for lymphocytes after incubation with $10 \mathrm{~Gy}$ irradiated rho ${ }^{0}$ yeast cells (3.00 $\pm 0.98 \%$ - the chromatid type aberrations; $0.67 \pm 0.47 \%$ - the chromosome type aberrations, $p<$ 0.01 ) (Fig. 4). For lymphocytes after incubation with $1 \mathrm{~Gy}$ irradiated rho ${ }^{0}$ yeast cells difference between 
level of the chromosome and chromatid type aberrations were statistically insignificant $(1.33 \pm 0.66 \%$ - the chromatid type aberrations; $0.67 \pm 0.47 \%$ - the chromosome type aberrations, $p>0.05$ ).

\section{CONCLUSION}

Our findings show that the induction of bystander effect depends on existence of mitochondrial DNA and the normally functioning mitochondria. In this case, a manifestation of BE is evident and dose independent, while rho ${ }^{0}$ yeast cells induce bystander effect in lymphocytes only at a dose of $10 \mathrm{~Gy}$. However, the level of chromosomal aberration in lymphocytes were cultured with yeast rho ${ }^{0} 10 \mathrm{~Gy}$ significantly lower than when cocultured with yeast rho $^{+}$.

\section{References}

[1] Rzeszowska-Wolny J., Przybyszewski W., Widel M. European Journal of Pharmacology 625 (2009) 156-164.

[2] DeVeaux L., Durtschi L., Case J., Wells D. Mutat. Res. 597 (2006) 78-86.

[3] Zhou H., Randers-Pherson G., Waldern C., Vannais D., Hall E., Hei T. Proc. Natl. Acad. Sci. USA 97 (2000) 2099-2104.

[4] Chen S., Zhao Y., Han W., Zhao G., Zhu L., Wang J., Bao L., Jiang E., Xu A., Hei TK., Yu Z., Wu L.British Journal of Cancer 98 (2008) 1839-1844.

[5] Watson G., Lorimore S., Macdonald D., Wright E. Canser. Res. 60 (2000) 5608-5611.

[6] Yang G., Wu L., Chen L., Pei B., Wang Y., Zhan F., Wu Y., Yu Z., Radiat. Res. 167 (2007) 298-305.

[7] Daev E.V., Kazarova V.E., Vyborova A.M., Dukelskaya A.V., "Crimean Meeting” Proceedings of the Third International Conference Modern problems of genetics, radiobiology, radioecology and evolution, Alushta, 2010, (Dubna, JINR, 2010) pp. 55.

[8] Sroya R., Smith R., Seymour C., Mothersill C. Dose-Response 8 (2010) 317-330.

[9] Rushkovsky S., Vasylenko O., Pronina O. and Shepeta Y. Radioprotection, 43 (2008) 5.

[10] Leach KJ., Van Tuyle G., Lin PS., Schmidt-Ullrich R., Mikkelsen RB. Canser. Res., 61 (2001)3894-3901.

[11] Zubko M.K., Guillard S., Lydall D Genetics 168 (2004) 103-115.

[12] Tawn E.J., Holdsworth D. Mutagen induced chromosome damage in human lymphocytes. In: D. E. Rooney and B.H. Czepulkowski (Eds.) - Human Cytogenetics. Volume II. Malignancy and acquired abnormalities. A practical approach. (Irl press, Oxford, New York, Tokyo, 1991) pp. 189-208.

[13] Hsu T.C., Wu X., Trizna Z. Cancer Genet Cytogenet 87 (1996) 127-132.

[14] Sokal, R.R., and F.J. Rohlf. Biometry: The principles and practice of statistics in biological research. 3rd edition. (W.H. Freeman, New York, 1995) 